\title{
When is there a more-credible effect?
}

\author{
William J. Skylark*
}

August 15, 2021

\begin{abstract}
Hoorens and Bruckmüller (2015) reported that people are more likely to judge comparison statements to be true when the comparison is framed as $A$ is more than $B$ than when it is framed as $B$ is less than $A$. Skylark (2021) recently provided further evidence for this more-credible effect, but found that it did not emerge for all stimulus sets. In particular, there was very little effect of comparative when participants evaluated the truth of statements comparing the amount of land required to produce certain foodstuffs. The present report describes two further pre-registered studies that probe the generality of the more-credible effect. Study 1 used the same land-use comparisons as Skylark (2021) but increased the masses of the foodstuffs from 1 kilo to 1000 tons (the idea being that 'less than' framing might only reduce credibility when the compared quantities are large). A manipulation check found that the change in stated mass increased the subjective size of the items, but there was still little effect of comparative on judgments of truth: more-than statements were judged true about $3 \%$ more often than less-than statements, and the effect was not reliably different from zero. Study 2 asked people to judge the truth of statements comparing the $\mathrm{CO} 2$ production of pairs of countries selected from the most polluting countries in the world. A modest, 'significant' more-credible effect emerged, with more-than framing boosting perceived truth by approximately 5\%. Exploratory cross-study comparison indicated that the more-credible effect did not meaningfully differ between the two studies. The factors that determine when, and how far, more-than framing boosts the credibility of comparative statements remains an important topic for inquiry.
\end{abstract}

In many languages, speakers can frame the ordinal comparison of two magnitudes as "A is more than $B$ " or as " $B$ is less than A". Although these two frames provide the same information about the ordering of the items on the magnitude scale, they are not pragmatically equivalent: people's choice of comparative is shaped by a range of variables, and the choice of comparative shapes listeners' inferences about the compared items (see e.g., Bruckmüller et al., 2017; Choplin, 2010; Choplin \& Hummel, 2002; Matthews \& Dylman, 2014; Skylark, 2018; Skylark et al., 2018; for related work in which a target quantity is compared to a numeric value, see e.g., Halberg \& Teigen, 2009; Halberg et al., 2009; Teigen et al., 2007a, 2007b, Teigen, 2008; Zhang \& Schwarz, 2020.)

Of most importance to the current work, Hoorens and Bruckmüller (2015) reported that more-than framing elicited greater agreement than less-than statements, and this effect generalized to binary judgments of the truth/falsity of the statement. Skylark (2021) dubbed the effect of more/less framing on agreement and judgments of truth the more-credible effect (i.e., framing a comparison as "more than" leads the ordinal relationship to be perceived as more credible than when the same relationship is framed as "less than").

Hoorens and Bruckmüller (2015) proposed that the more-credible effect is a fluency effect. In this account, people prefer, and are more likely to agree with, "more

${ }^{*}$ Department of Psychology, University of Cambridge. wjm22@cam.ac.uk. than" statements because "more" is easier to process than "less" (see e.g., McGlone \& Tofighbakhsh, 2000).

Skylark (2021) recently replicated the more-credible effect using novel statements relating to environmental change and sustainability, and found some limited support for the fluency explanation. He also found some a stimulus set for which the more-credible effect did not emerge. In particular, his Study 3 had people make true/false judgments about statements describing the amount of land required to produce 1 kilo (or 1 litre) of each of two foodstuffs - e.g., "Producing a kilo of dark chocolate uses more than producing a kilo of pig meat". There was little indication of a meaningful more-credible effect (the overall proportion of "true" responses was $47.47 \%$ in the Less condition and $47.21 \%$ in the More condition). This was in contrast to his Studies 1 and 2, in which people had rated their agreement with a range of comparative statements (e.g., "For most old houses, installing roof insulation is more beneficial than installing double glazing" was judged true more often than "For most old houses, installing double glazing is less beneficial than installing roof insulation"). To check whether the null effect for Study 3 was a consequence of the response scale (true/false judgments, rather than the agreement rating task used for the stimuli of Studies 1 and 2), Skylark's Study 4 repeated his Study 1 but with participants making true/false judgments for each statement. A pronounced more-credible effect emerged (the overall proportion of "true" judgments was $37.50 \%$ in the Less condition and 
$53.49 \%$ in the More condition, a difference of $15.99 \%$ ). A cross-study comparison confirmed that the confidence intervals for the interaction between Study (i.e., stimulus set) and Comparative comfortably excluded zero. Skylark's Study 9 again used the land use comparisons, this time with each participant judging the truth of a single comparative statement (rather than a set of 10 or 12 sentences); as before, there was very little indication that the "more" framing boosted perceived truth (the overall proportion of "true" responses was $61.14 \%$ for the Less condition and $59.53 \%$ for the More condition). (In partial support of the fluency explanation, this study also found little difference in the reading times for the more-than and less-than versions of each statement - cf a fairly substantial difference for the stimulus sets that did produce the more-credible effect.)

The current report describes two experiments that sought to clarify the generality of the more-credible effect and why it did not emerge for the land use sentences. As discussed by Skylark (2021), there are many possibilities, but one notable issue is that the land use statements compare relatively small magnitudes (or magnitudes that may be perceived as small). Linguistics researchers have long asserted that "less" is reserved for comparisons of small items (it is "marked") whereas "more" can be used to compare items of any size (it is "unmarked"; e.g., Clark, 1969; Matthews \& Dylman, 2014). Correspondingly, "A is less than B" may carry the implication that both objects are small (i.e., it is parsed as "A is small and $B$ is small[er]", or something similar). For items such as the benefits of double glazing and loft insulation, this may seem like a violation - that is, both items may be regarded as substantially beneficial - leading to rejection of the less-than framing as false. But the claim "Producing a kilo of A uses less land than producing a kilo of B" might be judged acceptable because a kilo is regarded as requiring relatively little land (or, perhaps, because people have little sense of scale for the land required to produce a kilo of food and so are indifferent about whether that quantity is implied to be small by the comparative statement).

Following this logic, if the masses of the foodstuffs were increased substantially, a more-credible effect might emerge for the land use statements. Correspondingly, Study 1 of the present report used the same land-use comparisons and design as Skylark's (2021) Study 3, but with the mass of the foodstuffs increased by a factor of $10^{5}$ (i.e., from 1 kilo to 1000 tons). Study 2 sought further evidence regarding the generality of the more-credible effect by having people judge the truth of statements relating to $\mathrm{CO} 2$ production by different (highly polluting) countries.

\section{$1 \quad$ Study 1}

\section{Method}

All studies were conducted on-line using the Qualtrics survey software (https://www.qualtrics.com/uk/). Study 1 was pre-registered at https://aspredicted. org/97fw8.pdf

\section{Materials}

Study 1 modified the stimuli from Study 3 of Skylark (2021): each statement compared the land required to produce a pair of foodstuffs. The mass of each foodstuff was increased from one kilo (the value used in Skylark, 2021) to one thousand tons. The pairs of items are shown in Table 1.

\section{Design and Procedure}

The design and procedure was the same as Study 3 of Skylark (2021). The survey began with a "captcha" page to screen out automated responses, followed by a question asking "Is English your first language ("mother tongue")?. There followed an information sheet and consent form. Then participants were shown the following instructions:

"On the following pages you will be asked to judge whether some statements are true or false. Please answer based on your own knowledge - don't look anything up, and don't worry if you find it hard. Just do your best! Click continue to begin."

On each subsequent page participants were presented with a comparative statement (e.g., "Producing a thousand tons of dark chocolate uses more land than producing a thousand tons of pig meat"). Above the statement was written "Is the following statement:" and below it were two radio buttons labelled True and False. The comparative (more vs less) was a between-subjects factor; the truth of the statement (based on the values shown in Table 1) was randomized on each trial. The order of statements was also randomized. (Here and throughout, all randomization was set to use each option equally often.) After answering all 12 true/false questions participants were asked for their age, sex (male, female, or "prefer not to say"), and whether they had previously started the study ("Which of the following best describes you?" with response options "This is the first time I have attempted this survey", "I have previously started the survey, but did not finish it (e.g. the browser crashed. I lost progress and restarted)", and "I have previously completed this survey"). All questions required a response before the participant could progress to the next page.

\section{Participants}

Participants in all studies were recruited via Prolific (https://www.prolific.co/). The sampling procedure is described in the pre-registration documents and involved recruiting UK-resident participants aged 18-100 whose first language was English, with steps taken to block or exclude participants who had previously started the study or who had participated in similar studies in the past.

For Study 1 the final sample comprised 432 participants aged $18-75(M=33.9, S D=12.6), 284$ female, 143 male, 5 "prefer not to say".

\section{Results}

The data and analysis scripts for all studies are provided in the Supplementary Materials (https://osf. 
Table 1: Stimuli for Study 1.

\begin{tabular}{|c|c|}
\hline Item requiring more land & Item requiring less land \\
\hline Dark chocolate (68.96) & Pig meat (17.36) \\
\hline Rapeseed oil (10.63) & Bread (3.85) \\
\hline Cheese (87.79) & Cane sugar (2.04) \\
\hline Poultry meat (12.22) & Rolled oats (7.60) \\
\hline Eggs (6.27) & Palm oil (2.42) \\
\hline Peanuts (9.11) & Potatoes (0.88) \\
\hline Tofu (3.52) & Bananas (1.93) \\
\hline Beer (1.11) & Tomatoes $(0.80)$ \\
\hline Sunflower oil (17.66) & Citrus fruit (0.86) \\
\hline Milk (8.95) & Apples (0.63) \\
\hline Olive oil (26.31) & Wine (1.78) \\
\hline Rice (2.80) & Soymilk (0.66) \\
\hline \multicolumn{2}{|l|}{ Example statements: } \\
\hline \multicolumn{2}{|c|}{$\begin{array}{l}\text { More, True: Producing a thousand tons of dark chocolate uses } \\
\text { more land than producing a thousand tons of pig meat }\end{array}$} \\
\hline \multicolumn{2}{|c|}{$\begin{array}{l}\text { More, False: Producing a thousand tons of pig meat uses more } \\
\text { land than producing a thousand tons of dark chocolate }\end{array}$} \\
\hline \multicolumn{2}{|c|}{$\begin{array}{l}\text { Less, True: Producing a thousand tons of pig meat uses less land } \\
\text { than producing a thousand tons of dark chocolate }\end{array}$} \\
\hline \multicolumn{2}{|c|}{$\begin{array}{l}\text { Less, False: Producing a thousand tons of dark chocolate uses less } \\
\text { land than producing a thousand tons of pig meat }\end{array}$} \\
\hline \multicolumn{2}{|c|}{$\begin{array}{l}\text { Note. Values in parentheses are the land use, in } \mathrm{m}^{2} \text {, per kilo or } \\
\text { litre of the product, based on Poore \& Nemecek (2018); these values } \\
\text { were not shown to participants. }\end{array}$} \\
\hline
\end{tabular}

io/nx4we/). All analyses were conducted in R ( $\mathrm{R}$ Core Team, 2020) using the packages tidyverse (Wickham et al., 2019), Ime4 (Bates et al., 2015), parameters (Lüdecke et al., 2020), ez (Lawrence, 2016), psychReport (Mackenzie \& Dudschig, 2021), RColorBrewer (Neuwirth, 2014), and gridExtra (Auguie, 2017).

The top panel of Figure 1 plots the proportion of statements judged "true" for each pair of foodstuffs, organized by whether the statement was true or false. The bottom panel shows the mean proportions of True and False statements judged to be true by participants in the More and Less conditions; the error bars are $95 \% \mathrm{Cls}$ computed for a within-subject design using the approach described by Morey (2008).

Like in Skylark (2021), the data were analysed in two ways. First, following Hoorens and Bruckmüller (2015), the mean proportion of "true" responses to True and False statements was computed for each participant and submitted to a $2 \times 2$ mixed ANOVA (with Truth as a withinsubjects factor and Comparative as a between-subjects factor). Overall, participants responded "true" more often to True statements than to False ones, $F(1,430)=$ $12.16, p<.001, \eta_{p}^{2}=.028,95 \% \mathrm{Cl}=.008, .058$ (see Figure 1). However, there was little effect of Comparative, $F(1,430)=2.98, p=.085, \eta_{p}^{2}=.007,95 \%$ $\mathrm{Cl}=.000, .026$, and the interaction effect was not reliably different from zero, $F(1,430)=3.60, p=.058$, $\eta_{p}^{2}=.008,95 \% \mathrm{Cl}=.000, .028$. Averaging the mean proportion of "true" responses from the True and False conditions for each participant and then computing the mean for each comparative condition produced values of $47.23 \%$ for the Less condition and $49.98 \%$ for the More condition, a difference of $2.74 \%$. Simply calculating the overall proportion of "true" responses for participants in the Less and More conditions gave values of $47.08 \%$ and $50.23 \%$, respectively - a difference of $3.15 \%$.

Next, the data were submitted to a mixed effects logistic regression. Responses (coded 0 for "false", 1 for "true") were regressed on Comparative (coded -0.5 for Less, +0.5 for More), Truth (coded -0.5 for False, +0.5 for True) and their interaction. As in Skylark (2021), the model was "maximal" (Barr et al., 2013) - that is, it included random intercepts for participants and topics (pairs of foodstuffs), a by-participant random effect of Truth, and by-topic random effects of Truth, Comparative, and their interaction; random effects were correlated. The intercept was estimated to be $-0.056,95 \% \mathrm{Cl}$ $=-0.132,0.019, p=.143$. The effects of Truth, Comparative and their interaction all had confidence intervals that included zero: $B_{\text {Truth }}=0.227,95 \% \mathrm{Cl}=-0.306$, $0.760], p=.404 ; B_{\text {Comparative }}=0.138,95 \% \mathrm{Cl}=-$ $0.031,0.306], p=.110 ; B_{\text {Interact }}=0.222,95 \% \mathrm{Cl}=$ $-0.073,0.516], p=.140$. The discrepancy between the effect of Truth in the ANOVA and mixed effects models 
was also found by Skylark (2021) and presuambly reflects the heterogeneity of the effect across topics (which is ignored by the ANOVA) (e.g., Clark, 1973).

\section{Exploratory Comparison Skylark (2021)}

As an exploratory analysis, I compared the results of Study 1 with those of Study 3 of Skylark (2021), which was identical to Study 1 except for using the low-magnitude versions of the foodstuffs ( 1 kilo or litre rather than 1000 tons). To this end, I ran a $2 \times 2 \times 2$ mixed ANOVA with Study (Study 1, the "high magnitude" study, vs Study 3 of Skylark, 2021, the "low-magnitude" study) and Comparative (Less vs More) as between-subject factors, and Truth (False vs True) as a within-subject factor. Of most importance, there was no overall effect of Comparative, $F(1,860)=1.10, p=.295, \eta_{p}^{2}=.001$, $95 \% \mathrm{Cl}=.000, .008$, and no difference in the effect of Comparative between the two studies, $F(1,860)=2.16$, $p=.142, \eta_{p}^{2}=.003,95 \% \mathrm{Cl}=.000, .011$. There was an effect of Truth, $F(1,860)=57.04, p<.001$, $\eta_{p}^{2}=.062,95 \% \mathrm{Cl}=.039, .090$, which interacted with Study, $F(1,860)=7.70, p=.006, \eta_{p}^{2}=.009,95 \% \mathrm{Cl}$ $=.001, .022$. (For the low-magnitude Study, the overall mean proportion of "true" responses was $41.93 \%$ in the False condition and $52.95 \%$ in the True condition; in the high-magnitude study the corresponding proportions were $46.06 \%$ and $51.15 \%$ ). None of the other effects were "significant": main effect of Study, $F(1,860)=1.15$, $p=.284, \eta_{p}^{2}=.001,95 \% \mathrm{Cl}=.000, .008$; interaction between Comparative and Truth, $F(1,860)=1.00$, $p=.317, \eta_{p}^{2}=.001,95 \% \mathrm{Cl}=.000, .008$; three-way interaction, $F(1,860)=2.56, p=.110, \eta_{p}^{2}=.003,95 \%$ $\mathrm{Cl}=.000, .012$.

\section{Manipulation Check}

After running Study 1, I conducted an additional study to check that the manipulation of the magnitude of the foodstuffs was successful (i.e., that the 1000 ton value used in Study 1 was regarded as larger than the 1 kilo/ 1 litre value used in Study 3 of Skylark, 2021). The manipulation check study was pre-registered at https: //aspredicted.org/h4y2e.pdf.

\section{Method}

\section{Materials, Design and Procedure}

After initial screens like those in Study 1 (e.g., information sheet and consent form), participants were told "On the following pages you will be asked to indicate your sense of the sizes of various quantities. Please answer based on your own subjective sense of magnitude - don't look anything up, and don't worry if you find it hard. Just do your best! Click continue to begin." On each subsequent page they were told "Please indicate your subjective sense of the magnitude of the following quantity:
The amount of land used to produce [quantity of foodstuff]", followed by response options "Tiny", Very small", "Small", "Medium", "Large", "Very large", "Enormous". These response options were coded 1 to 7 . The foodstuffs were the 24 foods used in Study 1; the quantity was manipulated between subjects to be 1 kilo (or 1 litre, for liquids) or 1000 tons, with random assignment to condition. The order of the questions was randomized. After the last item, participants completed the same demographic questions as for Study 1.

\section{Participants}

The pre-registration describes the sampling procedure in detail. The final sample comprised 59 participants (24 male, 35 female) aged $18-58(M=28.0, S D=10.2)$.

\section{Results and Discussion}

As expected, the mean judgment was larger in the 1000 ton condition than in the 1 kilo condition, $M=5.12$, $S D=0.71$ and $M=3.8, S D=0.94$, Welch-corrected $t(55.46)=6.12, p<.001, d=1.57,95 \% \mathrm{Cl}=0.98$, 2.15. This pattern held for all 24 foodstuffs (the code provided in the Supplementary Materials produces the relevant output). Notably, the mean response in the 1000 ton condition corresponds to the response "Large". Thus, the manipulation was successful in presenting target quantities that were regarded as substantial, although there is scope for a stronger effect. It is worth bearing in mind that, in the manipulation check task, the items were likely to have been judged relative to one another (e.g., Matthews, 2013) and thus the effect of the magnitude manipulation on the absolute responses would be expected to be attenuated.

\section{Study 2}

Study 2 sought further information about the size of the more-credible effect when people judge the truth of sentences regarding factual statements about environmental issues. To this end, I presented participants with statements comparing the $\mathrm{CO} 2$ output for large countries with high levels of $\mathrm{CO} 2$ emissions.

\section{Method}

Study 2 was pre-registered at https://aspredicted. org/tt4rs.pdf

\section{Materials}

The estimated CO2 production in 2018 for 20 countries were obtained from the Our World in Data website (https://ourworldindata.org/). The data were filtered to include only countries with an ISO code and whose population was more than 1 million (and for which a population value was present in the dataset). The 20 countries with the highest $\mathrm{CO} 2$ productions in 2018 were then extracted and grouped into pairs with adjacent $\mathrm{CO} 2$ 


\section{Comparative Less More}
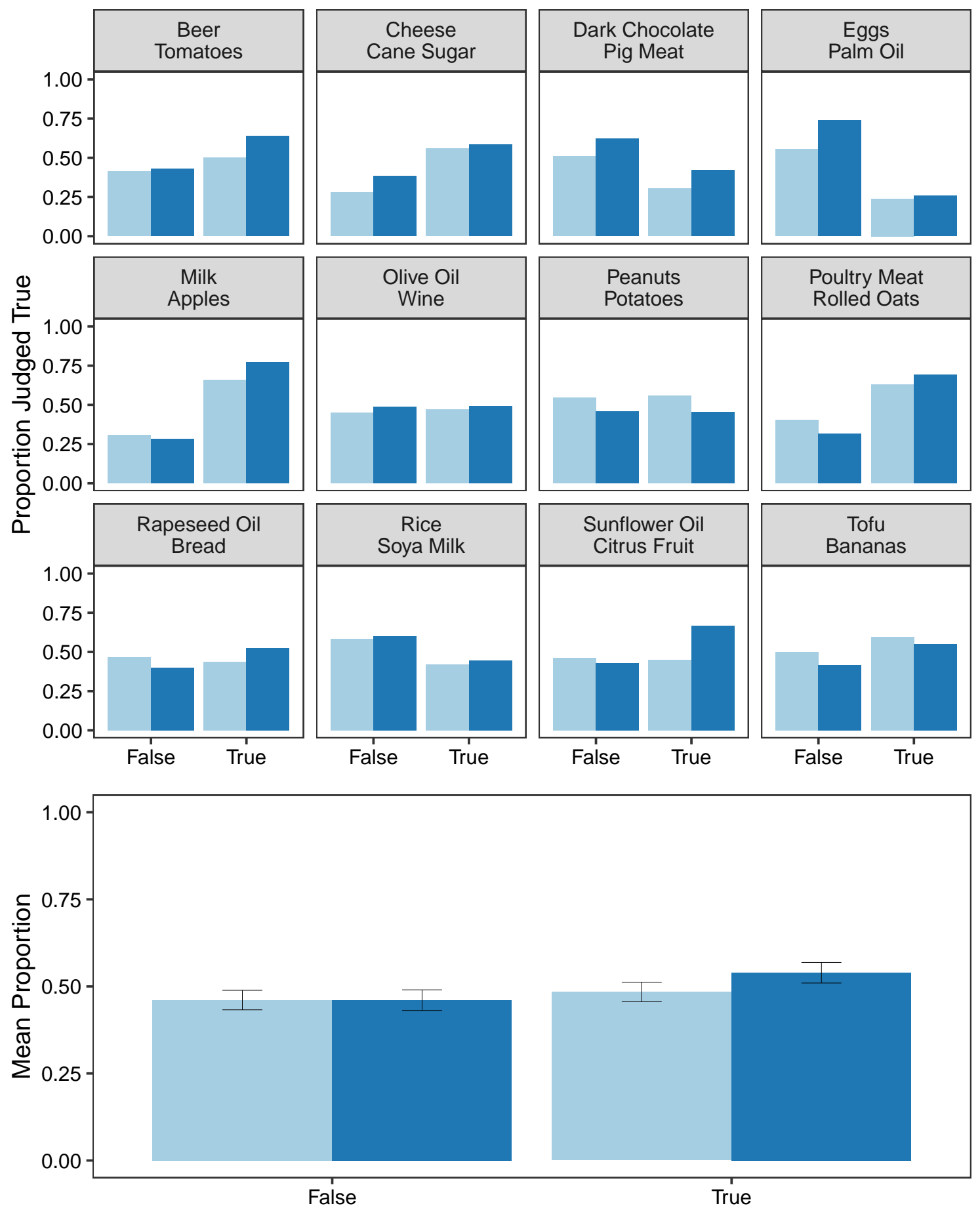

Figure 1: Results of Study 1. The top section shows the proportion of "true" responses for the True and False versions of each comparison with the More framing and the Less framing. The bottom panel shows the overall mean responses, as described in the main text, with $95 \%$ confidence intervals calculated for a within-subject design. 
emissions (e.g., China and the USA are the top pair, followed by India and Russia, and so on). The pairs are shown in Table 2 In this table, the values in parentheses are the estimated 2018 CO2 emissions for each country, based on a file downloaded from Our World in Data in the summer of 2020 and used as the basis for stimulus preparation. However, upon re-visiting the Our World in Data website in the summer of 2021 the data file seemed to have changed slightly (the github page suggests the data were updated in February, 2021: https://github.com/owid/co2-data). The revised figures do not change which of each of the presented pairs has the larger $\mathrm{CO} 2$ emissions, but they do mean that the pairs do not always comprise two countries with adjacent ranks. For example, the revised dataset suggests that the two least polluting countries are Poland (337.7 million tons) and France (331.7 million tons.

\section{Participants}

The sampling procedure was the same as for Study 1 and is described in full in the pre-registration. The final sample comprised 431 participants (275 female, 152 male, 4 "prefer not to say") aged 18-74 ( $M=33.9, S D=$ 12.8).

\section{Results}

Figure 2 shows the results in the same format as Figure 1. Applying the same analysis strategy as for Study 1 , a 2x2 ANOVA indicated a main effect of Comparative, $F(1,429)=13.98, p<.001, \eta_{p}^{2}=.032,95 \% \mathrm{Cl}=.010$, .063 , but no overall effect of Truth, $F(1,429)=2.49$, $p=.115, \eta_{p}^{2}=.006,95 \% \mathrm{Cl}=.000, .024$, and no interaction, $F(1,429)=0.03, p=.865, \eta_{p}^{2}=.000,95 \% \mathrm{Cl}$ $=.000, .005$. Averaging the mean proportion of "true" responses from the True and False conditions for each participant and then computing the mean for each comparative condition produced values of $48.82 \%$ for the Less condition and $53.89 \%$ for the More condition, a difference of $5.06 \%$. Simply calculating the overall proportion of "true" responses for the Less and More conditions produced values of $48.84 \%$ and $53.70 \%$, respectively - a difference of $4.87 \%$.

A mixed effects logistic regression analysis using the same approach was for Study 1 was flagged as singular. As described in the pre-registration, the model was therefore successively simplified and the results of both the full and reduced models are reported. For the full model (i.e., with maximal random effects), the intercept was $B=0.058,95 \% \mathrm{Cl}=0.000,0.116, p=.050$. Mirroring the ANOVA, the coefficient for Comparative was positive with $\mathrm{Cls}$ that excluded zero, $B=0.220,95 \% \mathrm{Cl}$ $=0.051,0.388, p=.011$; the coefficients for the effect of Truth and the interaction term had Cls that included zero, $B=0.090,95 \% \mathrm{Cl}=-0.691,0.871, p=.822$ and $B=-0.035,95 \% \mathrm{Cl}=-0.345,0.276, p=.826$, respectively. The reduced model dropped all random effects for participants, dropped the random intercept for topics, and had uncorrelated by-Topic random effects of Truth, Comparative and their interaction. The pattern of results was the same as for the full model (except that the Cls for the intercept now just included zero): for the intercept, $B=0.056,95 \% \mathrm{Cl}=-0.002,0.114, p=.056$; for Comparative, $B=0.215,95 \% \mathrm{Cl}=0.049,0.381, p=.011$; for Truth, $B=0.089,95 \% \mathrm{Cl}=-0.690,0.867, p=.824$; for the interaction, $B=-0.038,95 \% \mathrm{Cl}=-0.320,0.244$, $p=.793$.

In short, Study 2 produced a modest more-credible effect, although as indicated in Figure 2, it does not emerge consistently for all pairs of countries.

\section{Exploratory Comparison of Stud- ies 1 and 2}

Although Study 2 produced a non-zero more-credible effect whereas Study 1 did not, the size of the effects are quite similar in both studies (c. $2-3 \%$ in Study 1 vs c.4$5 \%$ in Study 2). An exploratory analysis directly compared the studies by running a $2 \times 2 \times 2$ mixed ANOVA with Study and Comparative as between-subjects factors and Truth as a within-subjects factor.

There was a main effect of Comparative, $F(1,859)=$ 13.96, $p<.001, \eta_{p}^{2}=.016,95 \% \mathrm{Cl}=.005, .032$, and this did not meaningfully differ between the studies, $F(1,859)=1.22, p=.269, \eta_{p}^{2}=.001,95 \% \mathrm{Cl}=$ $.000, .009$. There was also a main effect of Study (with slightly more "true" responses for Study 2 than Study 1: $51.4 \%$ vs $48.6 \%), F(1,859)=6.91, p=.009, \eta_{p}^{2}=.008$, $95 \% \mathrm{Cl}=.001, .021$, and a main effect of Truth (with $51.80 \%$ and $48.16 \%$ "true" responses to True and False statements, respectively), $F(1,859)=13.03, p<.001$, $\eta_{p}^{2}=.015,95 \% \mathrm{Cl}=.004, .031$. None of the other effects were reliably different from zero: Study $\times$ Comparative, $F(1,859)=1.22, p=.269, \eta_{p}^{2}=.001,95 \% \mathrm{Cl}$ $=.000, .009 ;$ Study $\times$ Truth, $F(1,859)=2.04, p=.154$, $\eta_{p}^{2}=.002,95 \% \mathrm{Cl}=.000, .011$; Comparative $\times$ Truth, $F(1,859)=1.57, p=.211, \eta_{p}^{2}=.002,95 \% \mathrm{Cl}=.000$, .010 ; three-way interaction, $F(1,859)=2.21, p=.137$, $\eta_{p}^{2}=.003,95 \% \mathrm{Cl}=.000, .011$.

\section{General Discussion}

These studies provide incremental data regarding the conditions under which the more-credible effect emerges. Study 1 suggests that greatly increasing the magnitudes of the compared items is not in itself sufficient to elicit a substantial more-credible effect, although this might be because the subjective magnitudes of the compared quantities was only, on average, "large": a stronger manipulation might have had a bigger effect. Study 2 found an overall more-credible effect whose confidence intervals excluded zero but which was of modest size and not "significantly" different from the effect in Study 1 . Study 2 therefore provides some evidence that the more-credible effect generalizes beyond the sets of stimuli used in Studies 1 and 2 of Skylark (2021). (One concern about those earlier stimuli is that they involve more ambiguous statements whose truth status is less clear, or even unknowable. The land use and $\mathrm{CO} 2$ production stimuli used here 


\section{Comparative Less More}
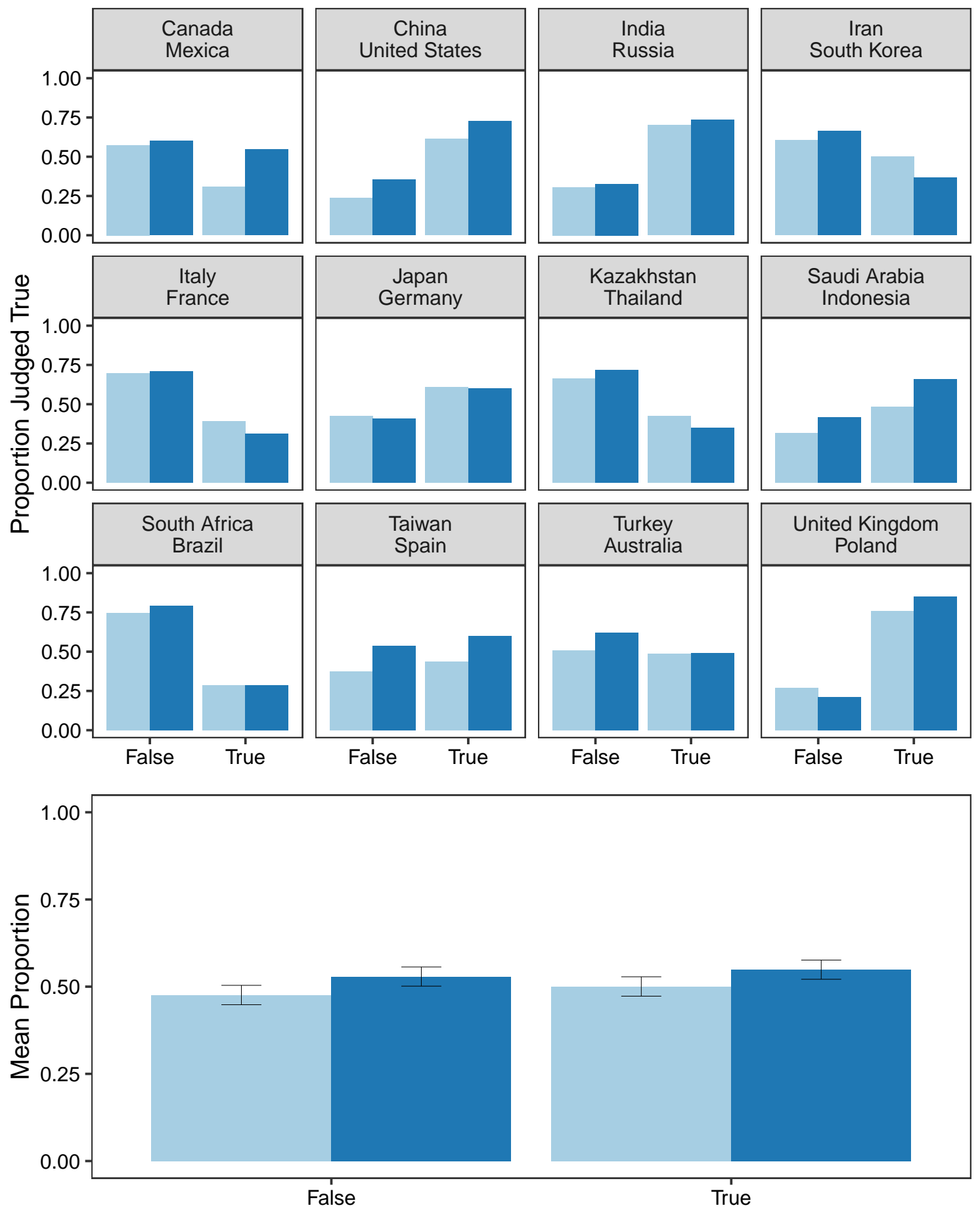

Figure 2: Results of Study 2. The top section shows the proportion of "true" responses for the True and False versions of each comparison with the More framing and the Less framing. The bottom panel shows the overall mean responses, as described in the main text, with $95 \%$ confidence intervals calculated for a within-subject design. 
Table 2: Stimuli for Study 2.

\begin{tabular}{ll}
\hline Country producing more CO2 & Country producing less CO2 \\
\hline China (10064.7) & USA (5416.3) \\
India (2654.1) & Russia (1710.7) \\
Japan (1162.0) & Germany $(759.0)$ \\
Iran (720.4) & South Korea (658.8) \\
Saudi Arabia (621.3) & Indonesia (614.9) \\
Canada (568.4) & Mexico (477.3) \\
South Africa (467.6) & Brazil $(457.2)$ \\
Turkey (428.2) & Australia $(420.2)$ \\
United Kingdom (379.0) & Poland $(343.5)$ \\
Italy (338.0) & France $(337.9)$ \\
\hline
\end{tabular}

Example statements:

More, True: China produces more CO2 than the USA

More, False: The USA produces more CO2 than China

Less, True: The USA produces less CO2 than China

Less, False: China produces less CO2 than the USA

Note. Values in parentheses are estimates of the CO2 production, in millions of tons, in 2018; these values were not shown to participants.

are "factual", although there is of course some epistemic uncertainty - a point driven home by the fact that the CO2 data for Study 2 seem to have been updated since the stimuli were first prepared.) The fact that the items compared in Study 2 were all (presuambly) regarded as quite large (involving some of the most polluting countries in the world) might be taken as indirect support for the importance of magnitude as a moderator of the effect. Still, the role of subjective magnitude in the more-credible effect remains unclear.

I did not repeat the subjective-magnitude rating task (used in the manipulation check for Study 1) for Study 2 , or for the stimulus sets that produced a more-credible effect in Skylark (2021). It might be productive to do so. However, although the manipulation check provides reassurance that the increase in objective magnitudes had the intended effect, it is difficult to be confident that questions about how big something is (or how big it seems) are tapping a stable underlying sense of magnitude: responses are affected by the elicitation process, contextual stimuli, and other recent responses (e.g., Matthews, 2012; Matthews \& Stewart, 2009; Skylark et al., 2021); correspondingly it is hard to know whether the responses to questions about subjective size in one task reflect the perceptions and beliefs that underlie performance in another.

In summary, the conditions under which the morecredible effect emerges, and the determinants of the size of the effect, remain unclear and a topic for further empirical work. Rather than speculate further at this point, the present studies are presented in the hope that researchers interested in this topic might find them useful.

\section{References}

Auguie, B. (2017). gridExtra: Miscellaneous Functions for "Grid" Graphics. R package version 2.3. https: //CRAN.R-project.org/package=gridExtra

Barr, D. J., Levy, R., Scheepers, C., \& Tily, H. J. (2013). Random effects structure for confirmatory hypothesis testing: Keep it maximal. Journal of Memory and Language, 68(3), 255-278. https://doi.org/10.1016/ j.jml.2012.11.001

Bates, D., Mächler, M., Bolker, B. M., \& Walker, S. C. (2015). Fitting linear mixed-effects models using Ime4. Journal of Statistical Software, 67(1), 1-48. https: //doi.org/10.18637/jss.v067.i01

Bruckmüller, S., Reese, G., \& Martiny, S. E. (2017). Is higher inequality less legitimate? Depends on how you frame it! British Journal of Social Psychology, 56(4), 766-781. https://doi.org/10.1111/bjso.12202

Choplin, J. M. (2010). I am "fatter" than she is: Language-expressible body-size comparisons bias judgments of body size. Journal of Language and Social Psychology, 29(1), 55-74. https://doi.org/ 10.1177/0261927X09351679

Choplin, J.M., \& Hummel, J.E. (2002). Magnitude comparisons distort mental representations of magnitude. Journal of Experimental Psychology: General, 131(2), 270-286. https://doi.org/10.1037/0096-3445. 131.2 .270

Clark, H. H. (1969). Linguistic processes in deductive reasoning. Psychological Review, 76(4), 387-404. https://doi.org/10.1037/h0027578

Clark, H.H. (1973). The language-as-fixed-effect fallacy: A critique of language statistics in psychological research. Journal of Verbal Learning and Verbal Behav- 
ior, 12(4), 335-359. https://doi.org/10.1016/ S0022-5371(73)80014-3

Halberg, A-M., \& Teigen, K.H. (2009). Framing of imprecise quantities: When are lower interval bounds preferred to upper bounds? Journal of Behavioral Decision Making, 22, 490-509. https://doi.org/10.1002/ bdm.635

Halberg, A-M., Teigen, K.H., \& Fostervold, K.I. (2009). Maximum vs. minimum estimates: Preferences of speakers and listeners for upper and lower limit estimates. Acta Psychologica, 132, 228-239. https: //doi.org/10.1016/j.actpsy.2009.07.007

Hoorens, V., \& Bruckmüller, S. (2015). Less is more? Think again! A cognitive fluency-based more-less asymmetry in comparative communication. Journal of Personality and Social Psychology, 109(5), 753-766. https://doi.org/10.1037/pspa0000032

Lawrence, M. A. (2016). ez: Easy analysis and visualization of factorial experiments ( $R$ package version 4.4-0). https://cran.r-project.org/package=ez

Lüdecke, D., Ben-Shachar, M., Patil, I., \& Makowski, D. (2020). Extracting, computing and exploring the parameters of statistical models using R. Journal of Open Source Software, 5(53), 2445. https://doi. org/10.21105/joss.02445

Mackenzie, I.G., \& Dudschig, C. (2021). psychReport: Reproducible reports in psychology. R package version 3.0.1. https://CRAN.R-project.org/ package $=$ psychReport

Matthews, W.J. (2012). How much do incidental values affect the judgment of time? Psychological Science, 23, 1432-1434. https://doi.org/10.1177/ 0956797612441609

Matthews, W.J. (2013). Relatively random: Context effects on perceived randomness and predicted outcomes. Journal of Experimental Psychology: Learning, Memory, and Cognition, 39, 1642-1648. https: //doi.org/10.1037/a0031081

Matthews, W. J., \& Dylman, A. S. (2014). The language of magnitude comparison. Journal of Experimental Psychology: General, 143(2), 510-520. https:// doi.org/10.1037/a0034143

Matthews, W. J., \& Stewart, N. (2009). Psychophysics and the judgment of price: Judging complex objects on a non-physical dimension elicits sequential effects like those in perceptual tasks. Judgment and Decision Making, 4, 64-81.

McGlone, M. S., \& Tofighbakhsh, J. (2000). Birds of a feather flock conjointly(?): Rhyme as reason in aphorisms. Psychological Science, 11(5), 424-428. https://doi.org/10.1111/1467-9280.00282

Morey, R.D. (2008). Confidence intervals from normalized data: A correction to Cousineau (2005). Tutorial in Quantitative Methods for Psychology, 4(2), 61-64.

Neuwirth, E. (2014). RColorBrewer: ColorBrewer Palettes. $\mathrm{R}$ package version 1.1-2. https://CRAN. R-project.org/package=RColorBrewer

Poore, J., \& Nemecek, T. (2018). Reducing food's environmental impacts through producers and consumers. Science, 360(6392), 987-992. https://doi.org/10. $1126 /$ science. aaq0216
R Core Team. (2020). R: A language and environment for statistical computing. https://www.r-project. org/

Skylark, W. J. (2018). If John is taller than Jake, where is John? Spatial inference from magnitude comparison. Journal of Experimental Psychology: Learning, Memory, and Cognition, 44(7), 1113-1129. https: //doi.org/10.1037/xlm0000505

Skylark, W.J. (2021). More is easier? Testing the role of fluency in the more-credible effect. Judgment and Decision Making, 16(3), 638-686.

Skylark, W. J., Carr, J. M., \& McComas, C. L. (2018). Who says "larger" and who says "smaller"? Individual differences in the language of comparison. Judgment and Decision Making, 13(6), 547-561.

Skylark, W.J., Farmer, G.D., \& Bahemia, N. (2021). Inference and preference in intertemporal choice. Judgment and Decision Making, 16(2), 422-459.

Teigen, K.H. (2008). More than $X$ is a lot: Pragmatic implicatures of one-sided uncertainty intervals. Social Cognition, 26(4), 379-400. https://doi.org/10. 1521/soco.2008.26.4.379

Teigen, K.H., Halberg, A-M., \& Fostervold, K.I. (2007a). Single-limit interval estimates as reference points. Applied Cognitive Psychology, 21, 383-406. https: //doi.org/10.1002/acp.1283

Teigen, K.H., Halberg, A-M., \& Fostervold, K.I. (2007b). More than, less than, or minimum, maximum: How upper and lower bounds determine subjective intervals estimates. Journal of Behavioral Decision Making, 20, 179-201. https://doi.org/10.1002/bdm.549

Zhang, Y.C., \& Schwarz, N. (2020). Truth from familiar turns of phrase: Word and number collocations in the corpus of language influence acceptance of novel claims. Journal of Experimental Social Psychology, 103999. 1-6. https://doi.org/10.1016/j.jesp. 2020.103999 